\title{
Faculty Approaches to Working Life Issues in Engineering Curricula
}

Mrs. Marie Magnell, KTH Royal Institute of Technology

$\mathrm{PhD}$ student at KTH

Dr. Lars Allan Geschwind, KTH Royal Institute of Technology

Dr. Lena B. Gumaelius, KTH, Department of Learning

Head of Deparment of Learning, ECE school, KTH PhD in Biotechnology 2001 Engineering degree in Chemistry 1994

\section{Prof. Anette Jepsen Kolmos, Aalborg University}

Anette Kolmos is Professor in Engineering Education and PBL and Chairholder for UNESCO in Problem Based Learning in Engineering Education, Aalborg University, Denmark. Guest professor at KTH Royal Institute of Technology and Guest Professor at UTM University Technology Malaysia 2011-2013. President of SEFI 2009-2011 (European Society for Engineering Education). Founding Chair of the SEFI-working group on Engineering Education Research. During the last 20 years, Dr. Kolmos has researched the following areas, primarily within Engineering Education: development and evaluation of project based and problem based curriculum, change from traditional to project organized and problem based curriculum, development of transferable skills in PBL and project work, and methods for staff development. She is Associate Editor for the European Journal of Engineering Education and was Associated Editor for Journal of Engineering Education (ASEE). Involved in supervision of $13 \mathrm{PhD}$ projects and published around 200 publications. Member of several organizations and committees within EER, national government bodies, and committees in the EU. 


\title{
Faculty Approaches to Working Life Issues in Engineering Curricula
}

\begin{abstract}
The purpose of this paper is to identify faculty approaches to working life issues in engineering education. The paper focuses on faculty attitudes towards working life issues and their integration into the curriculum and on activities related to working life introduced to the curriculum. We used a mixed methods approach and performed a survey and interviews at a single faculty research intensive technical university in Sweden. The results show that faculty members are positive towards integrating issues from working life into the curriculum. The findings show no support for the academic drift hypothesis, at least not as regards staff drift. The findings also show that faculty members with more work experience outside academia are more interested in including work related issues in their teaching, while faculty with less work experience are less interested. Faculty rate critical thinking, problem solving, new solutions and technical knowledge as the most important knowledge, skills and competences in the engineering profession. The most common ways to integrate working life issues are to use examples from their own work experience, guest lectures or case studies, while programs with more extensive connections to industry offer more integrated activities, e.g. projects with industry. Programs with more extensive connections to industry also seem to use professional contacts established through research in their teaching.
\end{abstract}

\section{Introduction}

Many research intensive higher education institutions are balancing demands and expectations from internal and external stakeholders. Governmental bodies, accreditations institutions, engineering professional organizations, students and industry demand an increase of connections to industry and the world of work in engineering education. On the other side, academia moves more in a direction of research and has a career path based on primarily research criteria and with less recognition of experience from working life ${ }^{1,2}$.

The purpose of this paper is to identify faculty approaches to industry connections and working life issues in engineering education. The research questions are: a) What are faculty attitudes towards working life issues and their integration into the curriculum? and b) What activities related to working life do faculty members introduce to the curriculum?

These research questions are based on the assumption that faculty attitudes and curricular activities related to working life are important factors in engineering education if we want to ensure that students are well prepared for a professional career as engineers.

\section{Literature Review}

In higher education and in professional education in particular, e.g. in medicine, agriculture and engineering, there is an ongoing change from a practical orientation to a more theoretical focus. This change has been described as academic drift, i.e. "a shift from ... vocational objectives towards more theoretically oriented academic values and attitudes”2 (p. 286) or "the process whereby knowledge which is intended to be useful gradually loses close ties to practice while becoming more tightly integrated with one or other body of scientific knowledge"” (p. 413). Another concept describing this process is academization, defined as "a functional response to the need for more theory in the curriculum and better trained students to cope with the demands of an increasingly knowledge-based labour market”“4 (p. 136). 
Kyvik $^{2,4}$ presents a typology containing six levels of academic drift; “student drift, staff drift, programme drift, institutional drift, sector drift, and policy drift” (pp. 292-296, pp. 158-162). For example, staff drift refers to faculty members moving towards academic ambitions and a research orientation rather than an industrial focus, programme drift refers to educational programs enhancing a theoretical curricula rather than a professional focus, and policy drift refers to state authorities changing opinions on the purpose of higher education programs. According to Kyvik ${ }^{4}$, much of the literature describes academization as an obstacle e.g. when students are educated for a practical profession. Nevertheless, academization can also lead to enhanced quality in both research and teaching.

Within engineering education, there has been a long lasting debate, ever since the emergence of engineering education in the $19^{\text {th }}$ century, regarding whether there should be a practicebased orientation or a more theoretical focus. ${ }^{5}$ The structure and content of engineering education have emerged and developed differently across countries and regions. In Northern Europe two types have evolved; on the one hand "a practical education that recruits skilled craftsmen from industry and trades” (p. 220) and, on the other hand, "a university-like academic engineering education, typically differentiated from the more discipline-oriented university education in natural science" (p. 220). ${ }^{5}$ At times, there have been demands for increased theoretical focus, as well as for a more practical approach. ${ }^{6}$ This ongoing variability has been illustrated by the metaphor of a "swinging pendulum" in engineering education (p. 219). ${ }^{5}$

During the second half of the $20^{\text {th }}$ century, the research volume at technical universities increased, in some cases leading to the formation of a science base in engineering curricula, and in other cases, as in Europe, leading to a reinforcement of the theoretical science foundation. Since the 1970s, the pendulum has to some extent turned towards practice, as project courses, problem-based learning and complex tasks from engineering practice are implemented in the engineering curricula. Such methods were spread more widely during the 1990s. ${ }^{5}$ Despite this turn, the debate continued through the 1990 s and "critics complained that engineering education had drifted away from an earlier practical orientation, becoming increasingly irrelevant to actual needs” ${ }^{\prime 6}$ (p. 70). Nevertheless, the career structure in technical universities are increasingly emphasizing research. ${ }^{1}$ Consequently, there are different trends pointing at, on the one hand, an orientation towards practice and, on the other hand, an orientation towards research and theory.

Additionally, there is an ongoing discussion regarding the extent to which higher education in general should directly prepare students for the world of work or rather lay a broad foundation without having possible future professional roles in mind. ${ }^{7}$ This debate aside, preparation for the world of work and employability has become a priority across disciplines and higher education institutions. In Europe, this is manifest in the Bologna Process. ${ }^{8}$ The overall aim of the Bologna process is to create a common European Higher Education Area (EHEA) based on international cooperation and academic exchange. This includes the introduction of comparable degrees organized in a three-cycle structure (bachelor-master-doctorate) and the setting up of national qualifications frameworks that are compatible with the overarching framework of qualifications for the EHEA and to define learning outcomes for each of the three cycles. Another overarching aim is to better prepare students for their future careers. The Bologna Process has supported and been one of the overall governmental drivers for skills and competence development. ${ }^{8}$

Despite the political focus on employability, there are several studies pointing to a shortage of connections to the world of work in engineering education. ${ }^{9,10,11}$ Due to this lack of links to 
industry, governmental and professional organizations, both nationally and internationally, demand an increase of connections to working life and of employability issues. ${ }^{12,13}$ For instance, in the national evaluation of engineering programmes in Sweden in 2005, the peer reviewers concluded "The dialogue with stakeholders should be improved and the programmes should include more work placement than is the case today” (p. 5). ${ }^{14}$

Employability is often understood as the ability to get a job after graduation or, alternatively, as a set of skills, but Knight and Yorke ${ }^{15}$ suggest that there is additional meaning to the concept. They stipulate that employability consists of "making convincing claims in four areas:

- Understanding (propositional knowledge)

- Skillful practices (procedural knowledge)

- Efficacy beliefs (belief that one can make impact on situations)

- Metacognition (awareness of what one knows and can do, and of how one learns more)" (pp. $37-38) .{ }^{15}$

They also suggest that employability can be enhanced in several ways during the whole period of education, preferably by programme-wide activities. Such learning activities are designed for students to learn knowledge and skills valued in the world of work and these activities can be called work related learning. ${ }^{15}$

Work related learning activities can also be defined as "learning activities through which students experience activities which are based on, or derive from, the context of work or the workplace” (p. 225). ${ }^{16}$ Such activities can be work based (at a workplace), non-work based (not located at a workplace) and also overlapping. Work based activities include e.g. part time employment, voluntary work, placements and projects. Non-work based activities, which are in focus in this study, include e.g. case studies, role play, scenarios and projects. When it comes to the design of work related learning activities, Hills et al suggest identifying learning outcomes in terms of skills as well as required knowledge and understanding sought after by employers. ${ }^{16}$

Several approaches aiming at improving engineering education, e.g. the CDIO (ConceiveDesign-Implement-Operate) initiative, have been initiated to put more emphasis on the skills students need to be able to work as engineers. ${ }^{17}$ To ensure that students learn the desired skills, a number of active and experiential learning methods are recommended since "active learning methods engage students directly in thinking and problem-solving activities” (p. 140) and "active learning becomes experiential when students take on roles that simulate professional engineering practice"(p. 141), which can happen in e.g. projects with industry and case studies. ${ }^{18}$ Both in projects and case studies, students get the opportunity to work on real-world problems. When Boden describes how to adopt and implement active learning methods, as projects and case studies, several examples of actions focusing on enhancing faculty members' competence in skills are mentioned. ${ }^{19}$ One of the suggestions is to recruit new faculty members with experience from industry, another is to offer faculty members a possibility to work outside academia, e.g. by sabbaticals in industry.

\section{Methodology}

A mixed methods approach with a sequential explanatory design was conducted. ${ }^{20}$ We started with a quantitative data collection by sending out a questionnaire, and then, to examine questions on attitudes and activities in depth, we conducted a qualitative data collection by 
performing interviews. Each step was analyzed separately and eventually a final interpretation was conducted.

The questionnaire was constructed by the project group and a pilot was conducted prior to the distribution of the questionnaire. In a number of questions, we chose to use six point rating scales. Since people tend to avoid the extremes and tend to choose the mid-point ${ }^{21}$, we decided to offer a larger scale than e.g. a four or a five point scale, with no middle point, i.e. a six point scale. The questionnaire included questions on responsibilities, incentives and management priorities, and, as presented in this paper, attitudes and activities. It took about 10-15 minutes to reply. The questionnaire was sent to the faculty, 1030 recipients in total, in mid-December. During January, we sent two reminders, which gave the respondents a timeframe of six weeks in total to reply. The response rate was 35\%. A reasonable explanation for the rather low response rate could be the "survey fatigue" among faculty members, due to the growing number of questionnaires in academia. ${ }^{22}$

The results of the questionnaire were analyzed in SPSS and, in this paper, frequency tables and Chi-Square tests are presented.

To examine the variety of attitudes as well as the activities that the different programs are utilizing in depth, we have conducted qualitative interviews in three engineering programs. The three programs were chosen based on the results of the questionnaire, having limited or extensive connections to working life: one with limited connection to working life, i.e. program 1, and two with extensive connection to working life, i.e. program 2 and 3.

Table 1. Interviewees

\begin{tabular}{|l|l|l|}
\hline Program & Interviewees & Positions \\
\hline Program 1 & 4 (3 female, 1 male) & $\begin{array}{l}\text { 1 program leader, } 1 \text { head of undergraduate studies, } \\
1 \text { associate professor, 1 researcher }\end{array}$ \\
\hline Program 2 & 4 (1 female, 3 male) & 1 program leader, 1 assistant professor, 2 lecturers \\
\hline Program 3 & 4 (1 female, 3 male) & 1 program leader, 2 associate professors, 1 lecturer \\
\hline
\end{tabular}

The interviewees were chosen using the following procedure: We contacted each of the three program directors, made an appointment for an interview, and asked for names of additional faculty members to interview. In total, twelve semi-structured interviews were conducted, four in each of the three engineering programs (see table 1). The interviews lasted on average one hour, were recorded and fully transcribed in verbatim. NVivo was used to perform a thematic analysis of the interviews.

The study was conducted at a single faculty research intensive technical university in Sweden. The university runs approximately 100 bachelor and master programs, mainly professional programs in engineering for 14000 undergraduate students. The engineering curricula do not contain work placements. The extent of work related activities is, to a high degree, determined by each faculty member teaching in engineering courses. Therefore, faculty members' attitudes towards working life issues in curricula are important components.

\section{Findings}

\section{Attitudes to working life issues in engineering curricula}

Regarding the attitudes to including working life issues in teaching activities, the results of the questionnaire indicate that slightly more than half of the faculty members are interested or 
very interested in including work related issues in their teaching, while few, $12 \%$, have no or very little interest and one third are moderately interested, as presented in table 2 . Thus, a majority of faculty members show interest in including work related issues.

Table 2. Frequency table, viewpoint

\begin{tabular}{|l|c|c|c|c|c|c|c|}
\hline $\begin{array}{l}\text { Viewpoint on including } \\
\text { work related issues, \% }\end{array}$ & $\mathbf{1}$ & $\mathbf{2}$ & $\mathbf{3}$ & $\mathbf{4}$ & $\mathbf{5}$ & $\mathbf{6}$ & Median \\
\hline Faculty members & 3 & 9 & 13 & 20 & 30 & 26 & 5 \\
\hline
\end{tabular}

Scale: $1=$ not interested, $6=$ very interested.

Among faculty members, a majority also think there is a need for an increase of work related issues in their teaching, see table 3. Few of the respondents think it is not needed at all. Consequently, a majority is interested in including work related issues and a majority thinks an increase is needed. $22 \%$ state that it is enough already, possibly indicating that in some educational programs, there are extensive connections to industry.

Table 3. Frequency table, attitude

\begin{tabular}{|l|c|}
\hline Need for an increase of work related issues, \% \\
\hline Yes, very much & 18 \\
\hline Yes, to some extent & 55 \\
\hline No, there is enough already & 22 \\
\hline No, work related issues are not needed & 5 \\
\hline
\end{tabular}

During the interviews, the question of attitudes to work related issues came also to the fore. In all three programs, the responses are rather consistent and include statements regarding that a) it is important since it is a professional education, b) it is natural in their environment, and c) work related issues are needed since the students request it and get inspired and motivated by it.

"Yes, we have heard from the students that they want to know about ... the world of work ... Since it is a professional education, we have to have knowledge about industry..." (Program 1, interviewee 3)

"Well, my position is that it is important, as inspiration, but I also think connection to the real world as a whole is important, both to society, industry and governmental agencies..." (Program 1, interviewee 2)

"It is natural, not important but natural in our engineering education ... everything we do is characterized by contacts with companies, both in student projects and in research projects." (Program 2, interviewee 1)

"Yes, I think it is really important for the students to see it, since it is motivational... They get very motivated when they have projects from industry" (Program 2, interviewee 2)

"But it's a must-have, it's impossible to offer engineering education, which is a professional education, if we do not have connections to working life." (Program 3, interviewee 1)

"In my opinion, engineering education is a professional education in the sense that we train people who essentially are going to work in the private or public 
sector. We train professionals. So, do I think it is important? Yes, I think it is important. It's not a thing that you add on, it's the whole point." (Program 3, interviewee 4)

Hence, the interviewees confirm the positive attitude from the questionnaire to work related issues. All of them emphasize the professional aspect and the industrial focus of engineering education. Consequently, the interviewees seem to resist staff $d r i f t^{2,4}$. Additionally, they also take student motivation into account.

In program 3, one of the interviewees explicitly touches upon the question of academic drift ${ }^{2}$, 3,4 .

"If you read the policy documents on what an engineer is and should be, i.e. our goals (for engineering education), you find the word research in very many places, but to my knowledge nothing regarding relations to or preparations for working life or industry. ... I would say that something has happened with the formalities relating to engineering education which is hair-raising. In the eighties, it was obvious to everyone that what we were doing was to train engineers for a workplace, but it doesn't seem to be like that anymore."

(Program 3, interviewee 4)

Following the definitions of Kyvik, this comment exemplifies policy drift since it refers to the national system of qualifications. The interviewee seems to resist the academic drift in terms of not taking part in staff drift. ${ }^{2,4}$

In the questionnaire, we also asked about the faculty members' work experience during the last ten years outside academia in a profession related to their current field. The results indicate that half of the faculty members have work experience outside academia during the last decade and half have not. Table 4 presents a cross-tabulation with the variables "Viewpoint on including work related issues in your teaching" and "Work experience outside academia”.

Table 4. Cross-tabulation, viewpoint and work experience

\begin{tabular}{|c|c|c|c|c|c|}
\hline \multicolumn{2}{|l|}{ Cross-tabulation, count } & \multicolumn{3}{|c|}{$\begin{array}{l}\text { Viewpoint on including work } \\
\text { related issues in teaching }\end{array}$} & \multirow[t]{2}{*}{ Total } \\
\hline \multirow{4}{*}{$\begin{array}{l}\text { Work experience outside } \\
\text { academia, in a profession } \\
\text { related to your current field, } \\
\text { number of years during the } \\
\text { last ten years }\end{array}$} & & $1-2$ & $3-4$ & $5-6$ & \\
\hline & 0 & 29 & 57 & 84 & 170 \\
\hline & -5 & 7 & 46 & 76 & 129 \\
\hline & $6-10$ & 2 & 7 & 30 & 39 \\
\hline \multicolumn{2}{|l|}{ Total } & 38 & 110 & 190 & 338 \\
\hline
\end{tabular}

Scale: $1=$ not interested, $6=$ very interested

To find out whether the attitudes to including work related issues are dependent on the level of work experience, the Chi-Square test was undertaken, as presented in table 5. The result shows a statistically significant difference between the groups. When examining table 4 , it shows that faculty members with no work experience outside academia are less interested in including work related issues in their teaching, and consequently, faculty members with more work experience are more interested in including work related issues in their teaching. 
Table 5. Chi-Square Test, viewpoint and work experience

\begin{tabular}{|l|l|l|l|}
\hline Chi-Square Test & & & \\
\hline & Value & df & Asymp. Sig. (2-sided) \\
\hline Pearson Chi-Square & $17,824^{\mathrm{a}}$ & 4 &, 001 \\
\hline N of Valid Cases & 338 & & \\
\hline
\end{tabular}

(a: 1 cell, 11,1\%, have expected count less than 5 . The minimum expected count is 4,38 ).

With the purpose of examining attitudes to working life issues more in depth and to see which aspects faculty members regard as more important than others, the questionnaire also contained questions regarding how faculty members rate knowledge, competences and skills in the engineering profession. The results are presented in table 6.

Table 6. Frequency Table, rating of knowledge, competence and skills

\begin{tabular}{|l|c|c|c|c|}
\hline $\begin{array}{l}\text { Faculty members rating of knowledge, } \\
\text { competence and skills in the engineering } \\
\text { profession, \% }\end{array}$ & $\mathbf{1 - 2}$ & $\mathbf{3 - 4}$ & $\mathbf{5 - 6}$ & Median \\
\hline Critical thinking & 1 & 13 & 87 & 6 \\
\hline Problem solving & 1 & 15 & 85 & 6 \\
\hline & 1 & 16 & 84 & 5 \\
\hline Finding new solutions & 0 & 20 & 80 & 5 \\
\hline Knowledge in the chosen technical field & 1 & 21 & 77 & 5 \\
\hline Creativity & 1 & 23 & 76 & 5 \\
\hline Communication & 4 & 27 & 70 & 5 \\
\hline $\begin{array}{l}\text { To solve real world problems using principles } \\
\text { from the mathematical and natural sciences }\end{array}$ & 2 & 29 & 68 & 5 \\
\hline Team work & 6 & 28 & 65 & 5 \\
\hline Ethics & 4 & 33 & 63 & 5 \\
\hline Data analysis & 3 & 33 & 63 & 5 \\
\hline Engineering Tools & 9 & 42 & 48 & 5 \\
\hline Sustainability & & & & \\
\hline & 8 & 46 & 46 & 4 \\
\hline Societal context & 5 & 51 & 45 & 4 \\
\hline Natural sciences & 6 & 49 & 45 & 4 \\
\hline Mathematics & 7 & 47 & 45 & 4 \\
\hline Global context & 5 & 53 & 43 & 4 \\
\hline Leadership & 7 & 53 & 40 & 4 \\
\hline Engineering Design & 8 & 52 & 40 & 4 \\
\hline Conducting experiments & 11 & 66 & 23 & 4 \\
\hline Entrepreneurship & 14 & 65 & 21 & 4 \\
\hline Business & & & \\
\hline
\end{tabular}

Scale $1=$ not important at all; $6=$ =very important. Sorted by median value.

The results indicate that faculty members rate critical thinking and problem solving as the most important (median 6), see table 6 . This is followed by finding new solutions and technical knowledge (median 5). These four top-scores illustrate that the faculty value both the technical knowledge and the critical stance to the knowledge together with a value of being able to use the knowledge for problem solving, finding new solutions and solve real world problems using principles from the mathematical and natural sciences (median 5 ). The 
findings do not illustrate a traditional theoretical academic culture, but more a critical academic culture including the application of knowledge.

The second main priority relates more to process competences such as creativity, communication, team work and ethics, which are all skills and competences that have been emphasized in the engineering curricula during the last 15 years as a part of employability and the graduates' readiness for work life. These skills and competences seem to be well accepted among faculty.

What might be surprising in the results is the low priority that the respondents give to sustainability, natural science, mathematics, leadership, entrepreneurship and business. Sustainability is surprising as it is a formal requirement from government that sustainability is part of the official curriculum. Natural science and mathematics are somewhat surprising as science is the basis for engineering; however it seems that the respondents in this study clearly value the application more than the theory itself.

Finally, it is remarkable that leadership, entrepreneurship and business are all low ranked. These areas are all part of an employability orientation, especially that engineers are able to establish innovative companies, and lead innovation development. However, these are also part of a private company strategy and it seems that faculty in this study do not value these elements as much as the more academic critical aspects.

Additional Chi-Square tests were conducted to examine whether attitudes in table 6 are dependent on the respondents' working experience outside academia. There are no significant differences regarding most of the knowledge, skills and competences in table 6 in relation to work experience, except for natural sciences and mathematics. The result of a Chi-Square test shows a statistically significant difference between the groups as regards how they rate the importance of natural sciences $\left(\chi^{2}=11.479\right.$, d.f. $\left.=4, p=0.022\right)$. The results regarding the group with no work experience show that a larger number than expected rate natural sciences as very important, while fewer than expected of those with work experience rate natural sciences as very important. Similar results apply to how faculty rate the importance of mathematics $\left(\chi^{2}=11.342\right.$, d.f. $\left.=4, p=0.023\right)$. In the group with no work experience outside academia, the results show that a larger number than expected rate mathematics as very important.

Hence, there are nearly no significant differences between the groups on attitudes in table 6 , which we would have expected due to the results in table 4 . Nevertheless, there are two exceptions, regarding natural sciences and mathematics, and the results show that faculty members with no work experience outside academia to a larger extent than faculty with work experience rate natural sciences and mathematics as very important.

\section{Curriculum activities related to working life}

The questionnaire contained a question regarding the faculty members' professional contacts outside academia. More specifically we asked: "how many entrepreneurs or employees from the private/public sector (outside academia) have you interacted with in your teaching the past year?”. A quarter of the respondents had no professional contacts outside academia at all, one third of them had between one and three contacts, and $44 \%$ had four or more contacts. Among the interviewees, the number of contacts differs as follows: in program 1, interviewees have few contact people contributing to their teaching, of which most come from small businesses and start-ups. Instead, they have more professional contacts through their research activities. 
"I don't have a large network, I think. I am in contact with one company, and this is the one we have started. And in my research, I am in contact with four companies." (Program 1, interviewee 1)

In program 2 and 3, the majority have several contacts that contribute to their teaching. In program 3, the contacts were mainly from larger companies. Both in program 2 and 3, faculty also mentioned that they bring professional contacts from research into their teaching.

"Yes, there are of course some contacts. And then, in our research, we are very much applied ... we work with companies and that lead us to openings for (student) projects.” (Program 2, interviewee 2)

"I have my own network, which I actually think I have established through my research. ... A lot is in my research, but that's what I bring into my teaching." (Program 3, interviewee 1)

Thus, a method to expand the number of external professional contacts that can contribute to teaching, mentioned by some of the interviewees, is using contacts developed through research.

In the questionnaire, there were also questions regarding what kind of activities related to working life that faculty members have included in their teaching. The results, as presented in table 7, show that examples from the faculty members' own work experience, guest lectures and case studies are more frequently used than study visits and projects with industry. Other response options were placements and courses at workplaces, both seldom used (Median 1).

Table 7. Frequency Table, activities in curricula

\begin{tabular}{|l|c|c|c|c|}
\hline $\begin{array}{l}\text { Activities related to working life included } \\
\text { in their teaching, \% }\end{array}$ & $\mathbf{1 - 2}$ & $\mathbf{3 - 4}$ & $\mathbf{5 - 6}$ & Median \\
\hline Examples from your own work experience & 31 & 30 & 39 & 4 \\
\hline Guest lectures & 39 & 25 & 37 & 4 \\
\hline Case studies & 35 & 30 & 35 & 4 \\
\hline Projects with industry & 50 & 23 & 27 & 2 \\
\hline Study visits & 58 & 25 & 17 & 2 \\
\hline
\end{tabular}

Scale: $1=$ never, $6=$ very often.

The interviews show that in program 1 , the main activity related to working life is guest lectures, while program 2 uses their contacts for study visits and projects with industry and program 3 offers guest lectures and projects with industry.

"Yes, above all, I have the expert in ... that comes here and gives a lecture. I let (the students) get in touch with people from the outside world." (Program 1, interviewee 2)

"One activity we have is the field trips/study visits ... the purpose (for the students) is to learn more about the ... process.” (Program 2, interviewee 1)

"When we cooperate with industry in our project courses, it is well integrated in to the courses, and the industry can offer a complex reality and problems that are stated differently than in the literature. Industry can offer challenges and 
complex problems that our students get to work with in an academic setting." (Program 3, interviewee 2)

Hence, programs with extensive connections to industry seem to offer more integrated work related activities such as projects with industry.

\section{Conclusion and perspectives}

In this article we aimed to explore two questions: a) What are faculty attitudes towards working life issues and their integration into the curriculum? and b) What activities related to working life do faculty members introduce to the curriculum?

In general, the findings in the quantitative analysis indicate that faculty from this technical university are positive towards integrating issues from working life in the curriculum. A majority of faculty indicate that they are very interested in work related issues and nearly $3 / 4$ of the respondents find a need for increasing these elements in their teaching. The interviews confirm these findings. Furthermore, there are some critical viewpoints among the interviewees that the relation to work related issues should be natural in engineering education but that there is a trend going in the opposite direction, i.e. towards more theoretical and traditional academic curricula.

The findings confirm this concern as the study has identified work experience as a significant variable for the faculty's view on including work related issues in their teaching. The findings show that faculty members with less work experience outside academia are less interested in including work related issues in their teaching, while faculty members with more work experience are more interested in including work related issues in their teaching. This might be a serious concern for - at least - many of the European universities as there has been a trend to merge engineering colleges (bachelor level) with universities (master level). At the engineering colleges, many faculty members had a background in industry, whereas faculty at universities have $\mathrm{PhD}$ degrees and active research careers.

However, work experience does not, at least not to a large extent, seem to influence the respondents' ranking of knowledge, skills and competences in the engineering profession. The respondents do find critical thinking, problem solving, new solutions and technical knowledge as the most important ones followed by process skills and competences such as creativity, communication, etc. Working experience influences both the importance of natural science and mathematics and there is a significant difference between faculty without working experience outside university and faculty that have. Leadership and entrepreneurship are ranked lowest together with business. This might not mean that the respondents find it irrelevant in the curriculum, but it illustrates their understanding of relevant knowledge and skills in the engineering profession. These priorities of knowledge and skills in the engineering profession seem to differ from the formal educational policy in this area, which to a large degree emphasize entrepreneurship.

The most common way to integrate working life issues is by guest lectures or case studies, and less by projects with industry and study visits. The interviews indicate that programs with more extensive connections to industry offer more integrated activities, e.g. projects with industry, while the program with limited connection to industry offer mainly guest lectures. Programs with more extensive connections to industry also seem to use professional contacts established through research in their teaching. Thus, using contacts developed through research and to further develop guest lectures into more integrated activities as case studies or 
projects with industry are possible means to enhance connections to industry in engineering education.

The findings also illustrate that employability and work related issues can be interpreted in many different ways. Knight and Yorke ${ }^{15}$ suggest a broader understanding of employability as knowledge, skills, beliefs and metacognition and the analysis of the questionnaire and the interviews indicate that faculty value these different aspects as important elements in the development of engineering education.

In the findings from this study, there is no support as regards their attitudes for the academic drift hypothesis, at least not as regards staff drift ${ }^{2,4}$. The respondents come from a traditional technical university emphasizing theoretical technical knowledge where research criteria are dominant factors in the career structure. Nonetheless, the faculty members stress the importance of keeping the industrial focus. Seen in this perspective, the findings reveal a positive attitude to changing the teaching and the courses in direction of integrating more work related issues.

But on the other side, it might be highly relevant to develop institutional strategies for how to integrate more relevant experience from working life and strategies for how to train faculty for this in their teaching. Another instrument could be to offer faculty members possibilities to work in industry, e.g. sabbaticals in industry. The interest in including activities related to work life in their teaching might increase. This is also in line with the previously mentioned suggestion on enhancing faculty members' competence by giving them opportunities to work in industry ${ }^{19}$.

Hopefully, this paper has contributed to a deeper understanding of faculty attitudes towards work life issues and of approaches to integrate contacts to working life in engineering education as well as for obstacles and opportunities involved. The next step of our research will be to present results concerning roles, responsibilities and support structures as regards the integration of work related issues. We will also perform documentary studies of curricula to map the different kinds of work related activities integrated in the educational programs. Additionally, we will conduct interviews and send questionnaires to students in order to understand how they experience work related activities in the engineering education.

\section{Acknowledgments}

Some parts of this study were presented at the 9th International CDIO Conference, Massachusetts Institute of Technology and Harvard University School of Engineering and Applied Sciences, Cambridge, Massachusetts, June 9 - 13, 2013.

Bibliographical Information

1 Geschwind, L., \& Broström, A. (2014fc). Managing the teaching-research nexus: ideals and practice in research oriented universities, in press Higher Education Research and Development.

2 Christensen, S. H., \& Erno-Kjolhede, E. (2011). Academic drift in Danish professional engineering education. Myth or reality? Opportunity or threat?, European Journal of Engineering Education, 36, 3, 285-299. 
3 Harwood, J. (2010). Understanding Academic Drift: On the Institutional Dynamics of Higher Technical and Professional Education, Minerva, 48, 413-427.

4 Kyvik, S. (2009). The Dynamics of Change in Higher Education: Expansion and Contraction. Higher Education Dynamics 27, Springer, Netherlands.

5 Jorgensen, U. (2007). Historical Accounts of Engineering Education, in Crawley, E., Malmqvist, J., Ostlund, S., and Brodeur, D., Rethinking Engineering Education. The CDIO Approach, Springer, New York.

6 Harwood, J. (2006). Engineering Education between Science and Practice: Rethinking the Historiography, History and Technology, 22, 1, 53-79.

7 Teichler, U. (1999). Research on the relationship between higher education and the world of work: Past achievements, problems and new challenges, Higher Education, 38, 169-190.

8 Bologna Process - European Higher Education Area, Retrieved 18 Dec, 2013, www.ehea.info

9 Walther J., Kellam N., Sochacka N., and Radcliffe D. (2011). Engineering Competence? An Interpretive Investigation of Engineering Students' Professional Formation, Journal of Engineering Education, 100, 703-740.

10 Dunsmore, K., Turns, J., \& Yellin, J. M. (2011). Looking Toward the Real World: Student Conceptions of Engineering, Journal of Engineering Education, 100, 2, 329-348.

11 Royal academy of engineering, (2010). Engineering graduates for industry, Retrieved January 1, 2014 http://www.raeng.org.uk/education/scet/pdf/engineering_graduates_for_industry_report.pdf

12 Royal academy of engineering, (2007). Educating engineers for 21st century, Retrived January 1, 2014 http://www.raeng.org.uk/news/publications/list/reports/Educating_Engineers_21st_Century.pdf

13 Kontaktiviteter. Högskolornas verksamheter för utbildningarnas arbetslivsanknytning. Rapport 2012:23R

14 Högskoleverket (2006) Utvärdering av utbildningar till civilingenjör vid svenska universitet och högskolor. Rapport 2006:8 R

15 Knight, P., and Yorke, M. (2004). Learning, Curriculum and Employability in Higher Education, RoutledgeFalmer, London and New York.

16 Hills, J.M., Robertson, G., Walker, R., Adey, M. A., and Nixon, I. (2003). Bridging the Gap Between Degree Programme Curricula and Employability Through Implementation of Work-related Learning, Teaching in Higher Education, 8, 211-231.

17 Crawley, E., Malmqvist, J., Ostlund, S., and Brodeur, D. (2007). Rethinking Engineering Education. The CDIO Approach, Springer, New York.

18 Edstrom, K., Soderholm, D., \& Knutson Wedel, M. (2007). Teaching and Learning, in Crawley, E., Malmqvist, J., Ostlund, S., and Brodeur, D., Rethinking Engineering Education. The CDIO Approach, Springer, New York.

19 Boden, D. (2007). Adapting and Implementing a CDIO Approach, in Crawley, E., Malmqvist, J., Ostlund, S., and Brodeur, D., Rethinking Engineering Education. The CDIO Approach, Springer, New York.

20 Creswell, J. W. (2009). Research Design. Qualitative, Quantitative, and Mixed Methods Approaches, SAGE, Los Angeles London New Delhi Singapore.

21 Cohen, L., Manion, L., and Morrison, K. (2011). Research methods in Education, Routledge, New York.

22 Kyvik, S. (2013). Academic Workload and Working Time: Retrospective Perceptions Versus Time-Series Data, Higher Education Quarterly, 67, 2-14. 